\title{
Utilization of the Nasoseptal Flap for Repair of Cerebrospinal Fluid Leak after Endoscopic Endonasal Approach for Resection of Pituitary Tumors
}

\author{
Remi A. Kessler ${ }^{1}$, Tomas Garzon-Muvdi ${ }^{1}$, Eileen $\mathrm{Kim}^{1}$, Murugappan Ramanathan $\mathrm{Jr}^{2 *}$, Michael Lim* \\ Departments of ${ }^{1}$ Neurosurgery, ${ }^{2}$ Otolaryngology-Head and Neck Surgery, Johns Hopkins School of Medicine, Baltimore, MD, USA
}

Received August 9, 2018

Revised October 17, 2018

Accepted November 13, 2018

\section{Correspondence}

Remi A. Kessler

Department of Neurosurgery,

Johns Hopkins School of Medicine,

600 N. Wolfe Street, Pathology 509,

Baltimore, MD 21287, USA

Tel: +1-310-309-0610

Fax: +1-410-502-4954

E-mail: remi.kessler@icahn.mssm.edu

*These authors contributed equally to this work.
Background One of the most frequent complications after endoscopic endonasal approach (EEA) for resection of pituitary tumors is cerebrospinal fluid (CSF) leaks. With the introduction of the pedicled nasoseptal flap, the reconstruction of the skull base has improved significantly resulting in a decrease in the occurrence of persistent CSF leaks. We present our experience utilizing the pedicled nasoseptal flap technique after EEA for reconstruction of the skull base in cases where CSF leak was detected.

Methods Data for patients undergoing EEA for pituitary tumors was retrospectively reviewed. These included demographic, clinical, operative, radiographic, and pathological information. Incidence of post-operative complications and CSF leaks were recorded. Descriptive statistical analysis was performed.

Results Between 2008 and 2015, 67 patients and 69 hospital admissions with pituitary tumors underwent a nasoseptal flap to reconstruct a skull base defect at Johns Hopkins Hospital. The mean age at surgery was $54.5 \pm 14.2$ years. Fifty-two percent of patients were male. Forty-six percent of patients were white, 33\% African-American, and $12 \%$ belonged to other racial groups. There was an intraoperative CSF leak in 39\% of patients. Seventy percent of patients with an intraoperative CSF leak had a nasoseptal flap reconstruction of the skull base. There were zero postoperative CSF leaks.

Conclusion With the introduction of the pedicled nasoseptal flap for reconstruction of the skull base after EEA for resection of pituitary adenomas, the incidence of postoperative CSF leaks has decreased significantly. In this retrospective analysis, we demonstrate the effectiveness of the use of nasoseptal flap in repairing CSF leak after EEA.

Key Words Neoplasms; Neurosurgery; Skull base; Adenoma.

\section{INTRODUCTION}

Pituitary tumors constitute $10-15 \%$ of all primary intracranial neoplasms. Among sellar lesions, pituitary adenomas are the most frequent finding [1]. Surgical intervention is the first-line treatment for most patients with pituitary adenomas, with the exception of prolactinomas, in which dopamine agonists remain the best treatment option [2]. The endoscopic endonasal approach (EEA) is a minimally invasive surgical tech-

This is an Open Access article distributed under the terms of the Creative Commons Attribution Non-Commercial License (https://creativecommons.org/licenses/by-nc/4.0) which permits unrestricted non-commercial use, distribution, and reproduction in any medium, provided the original work is properly cited.

Copyright $\odot 2019$ The Korean Brain Tumor Society, The Korean Society for NeuroOncology, and The Korean Society for Pediatric Neuro-Oncology nique for the removal of sellar and parasellar lesions. It has been introduced over the last twenty years as an alternative to the traditional microscopic surgery [3]. EEA imparts superior exposure of the sella and the advantages include a wide panoramic view and enhanced visualization of relevant anatomical structures [4].

While the endoscopic approach has demonstrated a notable decrease in overall complication rate, the need for large dural openings and arachnoid can result in large skull base defects with moderate to high flow cerebrospinal fluid (CSF) leaks [57]. As a consequence of suprasellar extension distending the diaphragma sellae, postoperative CSF rhinorrhea is more common with resection of macroadenomas than microadenomas [8]. Complications involving CSF leakage can result in bacte- 
rial meningitis, pneumocephalus, and intracranial hypotension, and also increase hospital cost and length of stay [9].

It is recognized that success of the reconstruction method following dissection is a principal determinant of postoperative CSF leak incidence [10]. The introduction of pedicled, vascularized skull base repair, also known as the nasoseptal flap, is now widely used due to its versatility and capability of covering an area averaging $17.12 \mathrm{~cm}^{2}$ as determined by radiographic and anatomical studies [11]. In addition, it has dramatically decreased the incidence of postoperative CSF leaks following EEA, from more than $20 \%$ to less than $5 \%$. This level is approximate to that of open cranial base surgery [12-14].

In this study, we sought to investigate our institutional experience using pedicled nasoseptal flaps for reconstruction of the skull base after EEA where an intraoperative CSF leak was identified during resection of a pituitary tumor. We focused the study on postoperative complications, emphasized on approach-related factors related to these complications, and compared our experience with reports in the literature.

\section{MATERIALS AND METHODS}

\section{Patient population}

Under an IRB approved protocol (IRB \#00092610), medical records of patients with a diagnosis of pituitary macroadenoma or microadenoma that subsequently underwent EEA resection were retrospectively reviewed from 2008 to 2015 at Johns Hopkins Hospital. The review included demographic, clinical, operative, radiographic, and pathological information.

\section{Collected data}

The following baseline admission data were collected: age, gender, race, common comorbidities, symptoms and signs at presentation, symptom duration (months), Karnofsky Performance Status (KPS) score, and follow-up time (months). These comorbidities included hypertension, diabetes mellitus, obesity, coronary artery bypass grafts/stents, sleep apnea, and coronary artery disease. Data collected on symptoms and signs included presence of headache, decreased vision, diplopia, gait and/or balance problems, nausea and/or vomiting, Cushing's syndrome, and cranial nerve deficits.

Preoperative and post-operative laboratory results were collected, consisting of serum prolactin, serum adrenocorticotropic hormone (ACTH), serum thyroid-stimulating hormone (TSH), serum free thyroxine 4 (T4), serum growth hormone, and serum cortisol levels. The timing between pre- and post-operative laboratory sample testing at our institution is between $24-48$ hours. All aforementioned data was collected for each admission, if available. Number of admissions (n) is used to designate the total number of admissions with the data point in question used to calculate overall percentages. The closest available laboratory values to the date prior to surgery and following surgery were used as pre- and postoperative values. Radiologic data obtained included the largest dimension for each macroadenoma or microadenoma, as measured by MRI prior to surgery. In this study, microadenomas were defined as tumors measuring $10 \mathrm{~mm}$ or less, and macroadenomas as those exceeding $10 \mathrm{~mm}$.

The primary outcome measure was the incidence of a postoperative CSF leak following surgery with use of a nasoseptal flap for skull base reconstruction. The incidence of intraoperative CSF leaks and post-operatively acquired diabetes insipidus was also recorded. At Johns Hopkins, there is a tertiary care referral practice for pituitary tumors which encompasses many difficult-to-resect tumors referred by other neurosurgeons (suprasellar extension, tumors adherent to the arachnoid, revision cases, and secreting tumors), which generally can result in higher CSF leak rates compared to published rates. All CSF leaks were reported, including pinpoint or extremely low flow leaks. Our institution does not have a specific grading system other than using pinpoint/low flow, moderate flow, or high flow (opening a cistern or ventricle).

\section{RESULTS}

\section{Patient characteristics}

A total of 67 patients (69 hospital admissions) diagnosed

Table 1. Study population and associated demographics

\begin{tabular}{lc} 
Demographic characteristic & $\begin{array}{c}\text { Total number of admissions } \\
(\chi=69)\end{array}$ \\
\hline $\begin{array}{l}\text { Date range of admission } \\
\text { Age }(\mathrm{yr})\end{array}$ & $2008-2015$ \\
$\quad$ Mean & $54.5 \pm 14.2$ \\
Median & 54.6 \\
Sex & \\
Female & $33(48)$ \\
Male & $36(52)$ \\
Race & \\
African descent & $23(33)$ \\
Asian & $6(9)$ \\
Caucasian & $32(46)$ \\
Other & $8(12)$ \\
Follow-up time (mo.) $n^{*}=68$ & \\
Mean & $9.7 \pm 14.9$ \\
Median & 5.0 \\
\hline
\end{tabular}

Data are expressed as number (percentage) of admissions presenting with each variable or mean \pm SD. Percentages have been rounded and may not add up to $100 .{ }^{*} n$ indicates the number of admissions with available data. If no $n$ is specified, all admissions were included. 
with pituitary adenomas undergoing EEA surgical resection were identified (Table 1). The average age at time of surgery was 54.5 years (range 14-91), and the sex distribution was evenly distributed with $52 \%$ male and $48 \%$ female. There was a heterogeneous racial makeup patients, with $46 \%$ Caucasian, $33 \%$ of African descent, $9 \%$ Asian, and $12 \%$ belonging to other racial groups.

The most common comorbidity at presentation was hypertension, with $43 \%$ of patients, followed by sleep apnea (9\%), diabetes mellitus (7\%), and obesity (7\%). 52\% of patients presented with headache as a symptom, and $58 \%$ had a documented visual field deficit as determined by physical examination. The median symptom duration was six months, and the median KPS score was 90 (Table 2).

The majority (97\%) of patients had a macroadenoma with a mean largest dimension of $2.6 \mathrm{~cm}$ (Table 3). Of all patients who underwent surgical resection, $28 \%$ had a nasoseptal flap, $18 \%$ had fat grafts and packing of the sella, $10 \%$ had a lumbar

Table 2. Clinical presentations of pituitary adenoma patients

\begin{tabular}{lc}
\hline & $\begin{array}{c}\text { Number of patients } \\
\chi(\%)\end{array}$ \\
\hline Common comorbidities, $n^{*}=68$ & $29(43)$ \\
Hypertension & $6(9)$ \\
Sleep apnea & $5(7)$ \\
Diabetes mellitus & $5(7)$ \\
Obesity & $2(3)$ \\
CABG/Stents & $3(4)$ \\
CAD, $n=67$ & $35(52)$ \\
Headache, $n=67$ & $36(58)$ \\
Visual field deficit (sign), $n=62$ & $29(43)$ \\
Decreased vision (symptom), $n=67$ & $15(22)$ \\
Narrowed visual fields (symptom), $n=67$ & $9(13)$ \\
Gait/balance (symptom), $n=67$ & $8(12)$ \\
Diplopia, $n=67$ & $3(4)$ \\
Symptoms of Cushing's, $n=67$ & $3(5)$ \\
Cranial nerve III deficit, $n=66$ & $2(3)$ \\
Cranial nerve VI deficit & $2(3)$ \\
Nausea/vomiting, $n=67$ & \\
KPS score & $89.1 \pm 4.1$ \\
Mean & 90 \\
Median & \\
Symptom duration (mo.), $n=55$ & 6.0 \\
Mean & \\
Median & \\
Data & \\
&
\end{tabular}

Data are expressed as number (percentage) of admissions presenting with each variable or mean \pm SD. Percentages have been rounded and may not add up to 100 . $n$ indicates the number of admissions with available data. If no $n$ is specified, all admissions were included. CABG, coronary artery bypass grafting; CAD, coronary artery disease; KPS, Karnofsky Performance Status drain, and $4 \%$ had a free mucosal graft from the middle turbinate. Of those with nasoseptal flaps, $2 \%$ had accompanying fat grafts/packing, and none had a lumbar drain.

With reference to laboratory values, there was a remarkable mean decrease in prolactin levels preoperatively and postoperatively $(94.8 \mu \mathrm{g} / \mathrm{L}$ vs. $72.2 \mu \mathrm{g} / \mathrm{L})$. There was also a decrease in TSH levels, from $2.3 \mathrm{ng} / \mathrm{dL}$ to $1.7 \mathrm{ng} / \mathrm{dL}$ and in free T4 levels $(2.0 \mathrm{ng} / \mathrm{dL}$ to $1.1 \mathrm{ng} / \mathrm{dL})$. In contrast, there was a marked mean increase in ACTH $(18.7 \mathrm{pg} / \mathrm{mL}$ vs. $103 \mathrm{pg} / \mathrm{mL})$ and in cortisol levels $(11.5 \mu \mathrm{g} / \mathrm{dL}$ vs. $31.8 \mu \mathrm{g} / \mathrm{dL})$. The level of postoperative cortisol and ACTH were much higher than preoperative status. This increase may be correlated to the perioperative use of steroids, as well as the fact that hormones are highly susceptible to changes based on time of day in which labs are drawn.

\section{Patient outcomes and complications}

There were zero postoperative CSF leaks. Twenty-two percent of patients had a postoperative complication of diabetes

Table 3. Pituitary adenoma radiological, surgical, and laboratory results

\begin{tabular}{lc}
\hline & Number of patients \\
$\chi(\%)$
\end{tabular}

Data are expressed as number (percentage) of admissions presenting with each variable or mean \pm SD. Percentages have been rounded and may not add up to $100 .{ }^{*} n$ indicates the number of admissions with available data. If no $n$ is specified, all admissions were included. $\mathrm{ACTH}$, adrenocorticotropic hormone; TSH, thyroid-stimulating hormone; T4, thyroxine 4 
insipidus (Table 4). The mean follow-up time was nine months. A review of the existing literature is summarized in Table 5.

Table 4. Perioperative and postoperative complications

\begin{tabular}{lc}
\hline \multicolumn{1}{c}{ Complication } & $\begin{array}{c}\text { Number of patients } \\
\chi(\%)^{*}\end{array}$ \\
\hline Intraoperative CSF leak, $n^{\dagger}=69$ & $27(39)$ \\
Nasoseptal flap, $n^{\dagger}=27$ & $19(70)$ \\
Postoperative CSF leak, $n=69$ & $0(0)$ \\
Diabetes insipidus, $n=37$ & $8(22)$ \\
\hline
\end{tabular}

*Unless otherwise noted, data are expressed as number (percentage) of admissions presenting with each variable. Percentages have been rounded and may not add up to $100,{ }^{\dagger} n$ indicates the number of admissions with available data. If no $n$ is specified, all admissions were included. CSF, cerebrospinal fluid

\section{DISCUSSION}

The introduction of EEA for tumor resection has dramatically transformed the surgical treatment of complex pituitary pathologies. As a result, skull base tumors necessitating extensive resection with resultant dural defects led to the development of more robust repair techniques, including free vascular grafts, free synthetic non-cellular grafts, and vascularized pedicled nasoseptal flaps [11]. Regardless of the reconstructive technique applied, reviews indicate that postoperative CSF leak hovers at approximately $8.5 \%$ [15]. When the data are stratified for defect location, defect size, and degree of intraoperative CSF leak, the evidence demonstrates that vascularized reconstruction is super to avascular techniques. In a vast systematic review, Harvey et al. [16] analyzed 38 studies with 609 pa-

Table 5. Summary of the literature

\begin{tabular}{|c|c|c|c|}
\hline Author/year & Article type & Title & Main points \\
\hline $\begin{array}{l}\text { Van Zele and } \\
\text { Bachert } \\
2011[28]\end{array}$ & Review & $\begin{array}{l}\text { Endoscopic skull base reconstruction after } \\
\text { endoscopic endonasal approach }\end{array}$ & $\begin{array}{l}\text { Nasoseptal flaps have significantly reduced } \\
\text { morbidity and postoperative risk of CSF leaks } \\
\text { after EEA. }\end{array}$ \\
\hline $\begin{array}{l}\text { Eloy et al. } \\
2012[29]\end{array}$ & $\begin{array}{l}\text { Retrospective } \\
\text { review }\end{array}$ & $\begin{array}{l}\text { Salvage endoscopic nasoseptal flap repair of } \\
\text { persistent cerebrospinal fluid leak after open } \\
\text { skull base surgery }\end{array}$ & $\begin{array}{l}\text { Persistent CSF rhinorrhea can be safely repaired } \\
\text { using nasoseptal flap in previous open skull base } \\
\text { surgical patients. }\end{array}$ \\
\hline $\begin{array}{l}\text { Learned et al. } \\
2013 \text { [32] }\end{array}$ & $\begin{array}{l}\text { Retrospective } \\
\text { review }\end{array}$ & $\begin{array}{l}\text { MR imaging evaluation of endoscopic cranial } \\
\text { base reconstruction with pedicled nasoseptal } \\
\text { flap following endoscopic endonasal skull base } \\
\text { surgery }\end{array}$ & $\begin{array}{l}\text { Non-enhancing mucosal gap or displacement of } \\
\text { nasoseptal flap may indicate incomplete defect } \\
\text { coverage, identifying patients at risk for CSF } \\
\text { leak. }\end{array}$ \\
\hline $\begin{array}{c}\text { Husain et al. } \\
2013[30]\end{array}$ & $\begin{array}{l}\text { Retrospective } \\
\text { review }\end{array}$ & $\begin{array}{l}\text { Assessment of mucocele formation after } \\
\text { endoscopic nasoseptal flap reconstruction of } \\
\text { skull base defects }\end{array}$ & $\begin{array}{l}\text { Nasoseptal flaps are efficient for skull base repairs. } \\
\text { Although they carry risk of mucocele formation, } \\
\text { removal of mucosa from flap placement site } \\
\text { resulted in a } 0 \% \text { incidence of postoperative } \\
\text { mucocele formation in this cohort. }\end{array}$ \\
\hline $\begin{array}{l}\text { Eloy et al. } \\
2013[33]\end{array}$ & Case series & $\begin{array}{l}\text { Double flap technique for reconstruction of } \\
\text { anterior skull base defects after craniofacial } \\
\text { tumor resection: technical note }\end{array}$ & $\begin{array}{l}\text { Double flap skull base reconstruction provides } \\
\text { barrier of vascularized tissue to prevent CSF } \\
\text { leaks; this technique is viable if endoscopic } \\
\text { resection with anticipated postoperative } \\
\text { radiation. }\end{array}$ \\
\hline $\begin{array}{l}\text { Thorp et al. } \\
2014 \text { [11] }\end{array}$ & $\begin{array}{l}\text { Retrospective } \\
\text { review }\end{array}$ & $\begin{array}{l}\text { Endoscopic skull base reconstruction: a review } \\
\text { and clinical case series of } 152 \text { vascularized flaps } \\
\text { used for surgical skull base defects in the setting } \\
\text { of intraoperative cerebrospinal fluid leak }\end{array}$ & $\begin{array}{l}\text { Larger skull base defects with high intraoperative } \\
\text { CSF flow require thoughtful approach and } \\
\text { consideration for vascularized repair. }\end{array}$ \\
\hline $\begin{array}{l}\text { Hara et al. } \\
2015[34]\end{array}$ & $\begin{array}{l}\text { Retrospective } \\
\text { review }\end{array}$ & $\begin{array}{l}\text { Cranial base repair using suturing technique } \\
\text { combined with a mucosal flap for cerebrospinal } \\
\text { fluid leakage during endoscopic endonasal } \\
\text { surgery }\end{array}$ & $\begin{array}{l}\text { Graded cranial base repair method using the } \\
\text { dural suturing technique is simple and reliable. }\end{array}$ \\
\hline $\begin{array}{l}\text { Abou-Al-Shaar } \\
\text { et al. } 2017 \text { [31] }\end{array}$ & Case report & $\begin{array}{l}\text { Bolstering the nasoseptal flap using sphenoid } \\
\text { sinus fat packing: a technical case report }\end{array}$ & $\begin{array}{l}\text { Sphenoid sinus fat packing may be important } \\
\text { technical adjunct in bolstering the nasoseptal } \\
\text { flap against the ventral skull base in } \\
\text { perioperative period. }\end{array}$ \\
\hline
\end{tabular}

CSF, cerebrospinal fluid; EEA, endoscopic endonasal approach 
tients with large dural defects, in which approximately half underwent vascularized reconstruction and the other half underwent free graft reconstruction. This resulted in a statistically significant difference in CSF leak rate (6.7\% vs. $15.6 \%$ respectively).

Nasoseptal flaps offer notable flexibility to the surgeon in skull base repair, and their potential to overlay such a significant area has led to its widely accepted use. It has been noted that in patients who experienced high intraoperative CSF flow, postoperative CSF leak rates remain at $5.7 \%$ with the use of a nasoseptal flap [17]. In addition, Thorp et al. [11] noted a 3.3\% perioperative CSF leak rate and zero postoperative CSF leak rate among 152 vascularized flaps used for surgical skull base defects.

CSF fluid leakage can be categorized into low-flow type and high-flow type. Luginbuhl et al. [18] first described the term of "high-flow" leakage, which referred to regular CSF flow out intraoperatively due to a cisternal or ventricular opening defect. Low-flow CSF leaks have been previously defined as solely a few drops in the context of transitory increased intracranial pressure, such as coughing, standing up, or straining. The majority of CSF leakage following endoscopic sellar region surgery is low flow [19]. Lumbar drains are often applied intraoperatively, postoperatively, and on occasion even preoperatively to control or prevent CSF leaks, yet their placement remains controversial [20-22].

Our analysis of 69 hospital admissions revealed that the use of a nasoseptal flap for skull base reconstruction in EEA surgical resection for pituitary adenomas is effective at fixing intraoperative CSF leaks in the absence of a lumbar drain. Our results demonstrating no incidence of postoperative CSF leakage following use of a nasoseptal flap are also consistent with the existing neurosurgical literature. For patients who underwent an alternative form of repair, to include sphenoid fat packing and/or a lumbar drain, there were similarly no postoperative CSF leaks. This practice is well-documented and also in keeping with the literature on this topic [23-25]. Fat grafts are generally not preferable to use in circumstances of intraoperative CSF leaks, as they can cause difficulty at re-operation, are challenging to follow-up via MRI, and can result in hydrocephalus in high flow leaks [26,27].

Van Zele and Bachert [28] conducted a review of nasoseptal flap use for skull base reconstruction and determined that they are responsible for a significant reduction in risk and morbidity of postoperative CSF leaks following EEA. Eloy et al. [29] found that the integration of a vascularized pedicled nasoseptal flap to prevent persistent CSF rhinorrhea in patients who have undergone past open skull base surgery has the benefit of avoiding revision craniotomy whilst providing healthy tissue to reconstruct the skull base.
One concern during repair with a nasoseptal flap is that it may carry an innate risk of mucocele formation when deposited over mucosalized bone, and such it is important to meticulously remove all sellar and sphenoid mucosa before laying down a flap. However, Husain et al. [30] ascertained that strategic and diligent removal of the mucosa for the flap placement site produced a $0 \%$ incidence of postoperative mucocele formation in their cohort of 70 patients, and a $2.9 \%$ postoperative CSF leak rate. Furthermore, Abou-Al-Shaar et al. [31] reported on the use of sphenoid sinus fat packing during skull base reconstruction as a support to the nasoseptal flap. They determined that it may serve as a significant technical addition to sustain the nasoseptal flap against the ventral skull base during the early perioperative period.

In addition, Learned et al. [32] determined that EEA skull base reconstruction that employs a nasoseptal flap has a characteristic MRI appearance. Identifying patient at risk for CSF leaks can be accomplished via MRI, as a non-enhancing mucosal gap or displacement of the nasoseptal flap may indicate incomplete defect coverage [32].

In conclusion, the implementation of the pedicled nasoseptal flap for skull base reconstruction after EEA for resection of pituitary adenomas has resulted in a significant decrease in the incidence of postoperative CSF rhinorrhea. In this retrospective analysis, we present our institutional experience utilizing the nasoseptal flap and describe its effectiveness in preventing CSF leaks after EEA.

\section{Conflicts of Interest}

The authors have no potential conflicts of interest.

\section{REFERENCES}

1. Pennacchietti V, Garzaro M, Grottoli S, et al. Three-dimensional endoscopic endonasal approach and outcomes in sellar lesions: a singlecenter experience of 104 cases. World Neurosurg 2016;89:121-5.

2. Kopczak A, Renner U, Karl Stalla G. Advances in understanding pituitary tumors. F1000Prime Rep 2014;6:5.

3. Singh H, Essayed WI, Cohen-Gadol A, Zada G, Schwartz TH. Resection of pituitary tumors: endoscopic versus microscopic. J Neurooncol 2016;130:309-17.

4. Gondim JA, Schops M, de Almeida JP, et al. Endoscopic endonasal transsphenoidal surgery: surgical results of 228 pituitary adenomas treated in a pituitary center. Pituitary 2010;13:68-77.

5. Rotenberg B, Tam S, Ryu WH, Duggal N. Microscopic versus endoscopic pituitary surgery: a systematic review. Laryngoscope 2010;120: 1292-7.

6. White DR, Sonnenburg RE, Ewend MG, Senior BA. Safety of minimally invasive pituitary surgery (MIPS) compared with a traditional approach. Laryngoscope 2004;114:1945-8.

7. Cho DY, Liau WR. Comparison of endonasal endoscopic surgery and sublabial microsurgery for prolactinomas. Surg Neurol 2002;58:371-5; discussion 375-6.

8. Gondim JA, Almeida JP, Albuquerque LA, et al. Endoscopic endonasal approach for pituitary adenoma: surgical complications in 301 patients. Pituitary 2011;14:174-83.

9. Magro E, Graillon T, Lassave J, et al. Complications related to the en- 
doscopic endonasal transsphenoidal approach for nonfunctioning pituitary macroadenomas in 300 consecutive patients. World Neurosurg 2016;89:442-53.

10. Duz B, Harman F, Secer HI, Bolu E, Gonul E. Transsphenoidal approaches to the pituitary: a progression in experience in a single centre. Acta Neurochir (Wien) 2008;150:1133-8; discussion 1138-9.

11. Thorp BD, Sreenath SB, Ebert CS, Zanation AM. Endoscopic skull base reconstruction: a review and clinical case series of 152 vascularized flaps used for surgical skull base defects in the setting of intraoperative cerebrospinal fluid leak. Neurosurg Focus 2014;37:E4.

12. Brunworth J, Lin T, Keschner DB, Garg R, Lee JT. Use of the HadadBassagasteguy flap for repair of recurrent cerebrospinal fluid leak after prior transsphenoidal surgery. Allergy Rhinol (Providence) 2013;4: e155-61.

13. Hadad G, Bassagasteguy L, Carrau RL, et al. A novel reconstructive technique after endoscopic expanded endonasal approaches: vascular pedicle nasoseptal flap. Laryngoscope 2006;116:1882-6.

14. Esposito F, Dusick JR, Fatemi N, Kelly DF. Graded repair of cranial base defects and cerebrospinal fluid leaks in transsphenoidal surgery. Neurosurgery 2007;60(4 Suppl 2):295-303; discussion 303-4.

15. Soudry E, Turner JH, Nayak JV, Hwang PH. Endoscopic reconstruction of surgically created skull base defects: a systematic review. Otolaryngol Head Neck Surg 2014;150:730-8.

16. Harvey RJ, Parmar P, Sacks R, Zanation AM. Endoscopic skull base reconstruction of large dural defects: a systematic review of published evidence. Laryngoscope 2012;122:452-9.

17. Zanation AM, Carrau RL, Snyderman CH, et al. Nasoseptal flap reconstruction of high flow intraoperative cerebral spinal fluid leaks during endoscopic skull base surgery. Am J Rhinol Allergy 2009;23: 518-21.

18. Luginbuhl AJ, Campbell PG, Evans J, Rosen M. Endoscopic repair of high-flow cranial base defects using a bilayer button. Laryngoscope 2010;120:876-80.

19. Zhan R, Chen S, Xu S, Liu JK, Li X. Postoperative low-flow cerebrospinal fluid leak of endoscopic endonasal transsphenoidal surgery for pituitary adenoma--wait and see, or lumbar drain? J Craniofac Surg 2015; 26:1261-4

20. Samadani U, Huang JH, Baranov D, Zager EL, Grady MS. Intracranial hypotension after intraoperative lumbar cerebrospinal fluid drainage. Neurosurgery 2003;52:148-51; discussion 151-2.

21. Allen KP, Isaacson B, Purcell P, Kutz JW Jr, Roland PS. Lumbar subarachnoid drainage in cerebrospinal fluid leaks after lateral skull base surgery. Otol Neurotol 2011;32:1522-4.

22. Ackerman PD, Spencer DA, Prabhu VC. The efficacy and safety of preoperative lumbar drain placement in anterior skull base surgery. J
Neurol Surg Rep 2013;74:1-9.

23. Strickland BA, Lucas J, Harris B, et al. Identification and repair of intraoperative cerebrospinal fluid leaks in endonasal transsphenoidal pituitary surgery: surgical experience in a series of 1002 patients. J Neurosurg 2018;129:425-9.

24. Sanders-Taylor C, Anaizi A, Kosty J, Zimmer LA, Theodosopoulos PV. Sellar reconstruction and rates of delayed cerebrospinal fluid leak after endoscopic pituitary surgery. J Neurol Surg B Skull Base 2015;76:281-5.

25. Sade B, Mohr G, Frenkiel S. Management of intra-operative cerebrospinal fluid leak in transnasal transsphenoidal pituitary microsurgery: use of post-operative lumbar drain and sellar reconstruction without fat packing. Acta Neurochir (Wien) 2006;148:13-8; discussion 18-9.

26. García-Garrigós E, Arenas-Jiménez JJ, Monjas-Cánovas I, et al. Transsphenoidal approach in endoscopic endonasal surgery for skull base lesions: what radiologists and surgeons need to know. Radiographics 2015;35:1170-85.

27. McMoul ED, Tabaee A. Management of skull base defects: cerebrospinal fluid rhinorrhea, meningoencephalocele and endoscopic skull base surgery. In: Sataloff RT, Fried MP, Tabaee A, editors. Sataloff's comprehensive textbook of otolaryngology head and neck surgery-rhinology/ allergy and immunology. 1st ed. London: JP Medical Ltd; 2016. p.87196.

28. Van Zele T, Bachert C. Endoscopic skull base reconstruction after endoscopic endonasal approach. B-ENT 2011;7 Suppl 17:41-6.

29. Eloy JA, Kalyoussef E, Choudhry OJ, et al. Salvage endoscopic nasoseptal flap repair of persistent cerebrospinal fluid leak after open skull base surgery. Am J Otolaryngol 2012;33:735-40.

30. Husain Q, Sanghvi S, Kovalerchik O, et al. Assessment of mucocele formation after endoscopic nasoseptal flap reconstruction of skull base defects. Allergy Rhinol (Providence) 2013;4:e27-31.

31. Abou-Al-Shaar H, Zaidi HA, Cote DJ, Laws ER Jr. Bolstering the nasoseptal flap using sphenoid sinus fat packing: a technical case report. World Neurosurg 2017;99:813.e1-5.

32. Learned KO, Adappa ND, Loevner LA, Palmer JN, Newman JG, Lee JY. MR imaging evaluation of endoscopic cranial base reconstruction with pedicled nasoseptal flap following endoscopic endonasal skull base surgery. Eur J Radiol 2013;82:544-51.

33. Eloy JA, Choudhry OJ, Christiano LD, Ajibade DV, Liu JK. Double flap technique for reconstruction of anterior skull base defects after craniofacial tumor resection: technical note. Int Forum Allergy Rhinol 2013;3:425-30.

34. Hara T, Akutsu H, Yamamoto T, et al. Cranial base repair using suturing technique combined with a mucosal flap for cerebrospinal fluid leakage during endoscopic endonasal surgery. World Neurosurg 2015; 84:1887-93. 